\title{
Prognostic factors in intrauterine insemination cycles
}

\author{
Fernanda Sicchieri ${ }^{1}$, Aline Bomfim Silva ${ }^{1}$, Ana Carolina Japur de Sá Rosa e Silva ${ }^{1}$, Paula Andrea de Albuquerque \\ Sales Navarro ${ }^{1}$, Rui Alberto Ferriani ${ }^{1}$, Rosana Maria dos Reis ${ }^{1}$
}

\author{
${ }^{1}$ Sector of Human Reproduction, Department of Gynecology and Obstetrics - Ribeirão Preto Medical School, São \\ Paulo University, Brazil.
}

This study was presented in the $27^{\text {th }}$ Brazilian Congress of Human Reproduction.

\begin{abstract}
Objective: This study aimed to evaluate the clinical pregnancy rate of intrauterine insemination cycles in relation to patient age, cause of infertility, ovulation induction method, number of mature follicles and sperm with progressive motility.

Methods: This retrospective observational study included 237 intrauterine insemination cycles performed from 2011 to 2015 at the Assisted Reproduction Service of the Hospital das Clínicas of the Ribeirão Preto Medical School, University of São Paulo. Student's t-test was used to compare quantitative variables and the chi-square test was used to compare qualitative variables.

Results: Patient age was inversely and significantly correlated with pregnancy rates $(p=0.001)$ (Pregnant women $=32.56 \pm 5.64$ years, non-pregnant women $=$ $36.64 \pm 5.03$ years). Cause of infertility, ovulation induction method, number of mature follicles and sperm with progressive motility were not associated with pregnancy rates. The overall clinical pregnancy rate was $7.59 \%$. In the subgroup of patients ( $n=102$ cycles) considered ideal for intrauterine insemination (age $\leq 35$ years, unexplained infertility, ovarian factor infertility or minimal endometriosis, and a partner with sperm count $\geq 2.5 \times 10^{6}$ retrieved on the day of insemination) the pregnancy rate was $12.74 \%$.

Conclusion: In the studied group, female patient age was the only variable significantly correlated with intrauterine insemination success rates.
\end{abstract}

Keywords: intrauterine insemination, sperm motility, pregnancy rate

\section{INTRODUCTION}

Infertility is a public health concern that drives many couples to seek assisted reproductive technology (ART) therapies. However, due to the high cost of in vitro fertilization (IVF), less invasive and more affordable procedures such as intrauterine insemination (IUI) have become more popular (Ashrafi et al., 2013; Fauque et al., 2014). However, the distress associated with the treatment should be considered, since the procedure involves a strong emotional investment for the couple. Therefore, it is important to find the prognostic factors favoring IUI over IVF.

IUI is indicated in cases of unexplained infertility, male subfertility, unilateral tubal blockage, cervical or ovulatory dysfunction, and mild or minimal endometriosis (Azantee et al., 2011; Fauque et al., 2014). Despite the improvements in semen preparation and controlled ovarian stimulation techniques, the success rates reported for IUI are lower than the rates reported for other ART procedures (Ghaffari et al., 2015). Data from the European Society of Human Reproduction and Embryology showed that the pregnancy rate per cycle has remained stable for years at 12.4\% (Ferraretti et al., 2012; Dinelli et al., 2014). Global pregnancy rates as high as $30 \%$ have been reported in some studies on IUI, although results vary depending on the population studied (Luco et al., 2014; European IVF-Monitoring Consortium, 2016).

Regardless of the treatment used, couples are keen to know their chances of success. Therefore, it is crucial to identify and assess the factors that influence the attainment of pregnancy (Ghaffari et al., 2015). Several prognostic factors linked to the outcome of IUI have been identified and related to type of ovarian stimulation and couple characteristics such as female patient age, type and duration of infertility, number of mature follicles recruited, endometrial thickness, number of sperm with progressive motility, sperm morphology, and number of sperm used in insemination (Dinelli et al., 2014; Fauque et al., 2014; Ghaffari et al., 2015).

Since 1992, the Assisted Reproduction Service of the Hospital das Clínicas of the Ribeirão Preto Medical School of the University of São Paulo (HC-FMRP/USP) has offered ART and IUI with patients paying only for the medication used in the procedures. The service has recorded strong inflows of patients from the countryside of the State of São Paulo and other parts of Brazil. The high demand for the services at hand has fostered the development of systems to track the cost of each procedure. In order to encourage the use of low complexity over high complexity techniques, the clinical pregnancy rates of patients offered IUI from 2011 to 2015 in the Assisted Reproduction Service at HC-FMRP/USP was analyzed. Clinical pregnancy rates were then compared for ovulation induction method, cause of infertility, female patient age, number of mature follicles and sperm with progressive motility, in order to determine possible prognostic factors.

\section{MATERIAL AND METHODS}

\section{Patients and study design}

This retrospective observational study was carried out from an analysis of the data collected from 237 IUI cycles performed in 198 women treated from February of 2011 to December of 2015 in the Assisted Reproduction Service at HC-FMRP/USP. The study was conducted in accordance with the guidelines set by the ethics committee at HC-FMRP/USP and the tenets of the Declaration of Helsin$\mathrm{ki}$. The ethics committee approved the study design, and the need to obtain informed consent was waived due to the retrospective nature of the study. The included couples had been diagnosed with infertility and were assessed to determine the cause of infertility. The tests included seminograms to assess semen quality, hormone measurements to evaluate the presence of ovulation or menstrual disorders, analysis of the uterine cavity and tubal patency using pelvic ultrasonography and hysterosalpingography and/or hysteroscopy and videolaparoscopy. Assessment of vaginal infection through cytology and detection of couple viral infections through serology tests were also conducted. Treatments and ART procedures were chosen once the cause of infertility was established. Couples prescribed IUI had to have at least one permeable tube of normal diameter and a motile sperm concentration of $5 \times 10^{6} / \mathrm{mL}$ on the day of the seminogram. 


\section{Ovulation induction and insemination}

The induction of ovulation for IUI was performed according to the standard protocols in effect at the hospital: protocol 1 consisted of Clomiphene Citrate at a dose of 50 to $100 \mathrm{mg} /$ day for 5 days from the second or third day of the menstrual cycle, alone or combined with Gonadotropins - Follicle Stimulating Hormone (FSH) and Luteinizing Hormone (LH) - $\left(\right.$ Menopur $\left.{ }^{\circledR}\right)$ at a dose of 75 IU on alternate days from the second day of ovulation induction; protocol 2 consisted of Gonadotropins (Menopur ${ }^{\circledR}$ ) at a dose of $75 \mathrm{IU}$ or recombinant FSH (Gonal ${ }^{\circledR}$ or Puregon ${ }^{\circledR}$ ) at a dose of 50 to 75 IU on consecutive or alternate days from the second or third day of the menstrual cycle. Ovulation was monitored with transvaginal pelvic ultrasound, starting on the eighth day from the start of ovulation induction medication (Protocols 1 or 2). When a follicle reached a mean diameter of 17 to $18 \mathrm{~mm}$, Human Chorionic Gonadotropin (hCG) (Choriamon ${ }^{\circledR}$ ) was administered at a dose of 5000 IU or recombinant hCG (Ovidrel ${ }^{\circledR}$ ) was administered at a dose of $250 \mathrm{mg}$ for oocyte maturation, followed by IUI after 36 to 40 hours. For cases of ovulation induction for IVF using Gonadotropins at 150 to 300 IU/day, IUI was offered only when one or two follicles were recruited or when the patient had patent fallopian tubes and her partner had a motile sperm count of $5 \times 10^{6} / \mathrm{mL}$ on the day of the seminogram. The luteal phase was supplemented with Utroges$\tan ^{\circledR} 200 \mathrm{mg}$ or Duphaston ${ }^{\circledR} 20 \mathrm{mg}$ per day. Only 12 cycles occurred with no supplementation in the luteal phase.

\section{Semen preparation}

Semen preparation for IUI was performed through sperm washing or density gradient centrifugation. The first method was used for samples with sperm concentration $<10 \times 10^{6}$ regardless of motility, for samples with $\geq 50 \%$ immotile sperm regardless of concentration, and for thawed semen. Semen was added to Human Tubal Fluid (HTF) - 4-(2-hydroxyethyl)-1-piperazineethanesulfonic acid (HEPES) (Irvine Scientific) supplemented with $10 \%$ Serum Substitute Supplement (SSS) (Irvine Scientific) at the same proportion; the samples were then homogenized. The samples were centrifuged for 10 minutes at $1000 \mathrm{rpm}$. The supernatant was discarded and the resulting pellet diluted in $0.5 \mathrm{~mL}$ HTF-HEPES + $10 \%$ SSS.

The second method consisted of two protocols: $1.0 \mathrm{~mL}$ of colloidal suspension was used for samples with progressive motility $>32 \%$ and $0.5 \mathrm{~mL}$ for samples with progressive motility $<32 \%$. According to the protocol, $1.0 \mathrm{~mL}$ or $0.5 \mathrm{~mL}$ of $90 \%$ colloidal gradient was first added to the tube and $1.0 \mathrm{~mL}$ or $0.5 \mathrm{~mL}$ of $45 \%$ colloidal gradient was pipetted carefully onto the wall of the tube. Afterwards, a maximum of $3.0 \mathrm{~mL}$ of liquefied semen was deposited gently on top of the solution. The sample was centrifuged for 30 minutes at $1000 \mathrm{rpm}$, the supernatant discarded, and the pellet homogenized in $2.0 \mathrm{~mL}$ of HTF-HEPES + $10 \%$ SSS medium. A second centrifugation was performed to eliminate residual particles from the colloidal gradient, the supernatant was discarded, and the resulting sediment diluted in $0.5 \mathrm{~mL}$ of HTF-HEPES + SSS $10 \%$.

After sperm preparation, the new concentrations and sample motility were determined. The number of sperm with progressive motility to be inseminated was then calculated. Using a $1.0 \mathrm{~mL}$ syringe, a LABORATOIRE CCD (Paris-France) insemination catheter was filled with the resulting semen sample. The procedure was performed with the aid of abdominal and pelvic ultrasound guidance.

\section{Statistics}

Software package SAS version 9.3 (SAS Inc Cary, CN) was used for data analysis, with the level of significance set at $p<0.05$. Exploratory data analysis was performed using measurements of central tendency and scatter. Qualitative variables were described in terms of absolute numbers and proportions. Student's t-test was used to compare the groups with regard to quantitative variables. The distribution of variables was assessed through normal probability plots. The chi-square test was used for qualitative variables to test the null hypothesis of absence of association between qualitative variables and clinical pregnancy rates.

\section{RESULTS}

Two hundred and thirty-seven IUI cycles were performed, and 33 patients (14\%) underwent more than one cycle (two to four cycles). Clinical data such as patient age, number of follicles recruited on the day of hCG, and semen characteristics on the day of insemination are presented in Table 1.

The overall clinical pregnancy rate was $7.59 \%(n=18$ cycles). Laboratory and clinical parameters of the IUI cycles with regard to pregnancy outcomes are presented in Table 2. With the exception of age, there was no significant difference between the groups.

Quantitative analysis of the mature follicles recruited ( $\geq 17 \mathrm{~mm}$ ) during ovulation induction was conducted and results were compared for clinical pregnancy outcomes. Two or more mature follicles were recruited in only 30 patients $(12.6 \%)$. Among the patients who became pregnant, 16 had one mature follicle and two had two mature follicles.

In $75.5 \%$ of the cases ( $n=179$ cycles), ovulation induction was indicated and performed for IUI. IVF was initially indicated in $24.5 \%$ of cases ( $n=58$ cycles), but IUI was performed due to low follicular recruitment. The data on the cycles of these two subgroups are shown in Table 3.

The causes of infertility were categorized into seven subgroups. Table 4 shows that none of the causes was statistically correlated with clinical pregnancy rates.

Age was the only variable to present a statistically significant correlation $(p=0.001)$ with pregnancy. The mean age of the patients who achieved pregnancy was 32.56 ( \pm 4.64) (Figure 1). Clinical pregnancy rates from IUI had no statistically significant association with cause of infertility, number of mature follicles or sperm with progressive motility.

The subgroup of patients showing ideal conditions to undergo IUI was described as having age $\leq 35$ years and causes of infertility including unexplained infertility, ovarian factor infertility, minimal endometriosis, and partners with recovered sperm counts $\geq 2.5 \times 10^{6}$ on the day of insemination. In this subgroup, 102 IUI cycles were performed, or $43 \%$ of all cycles, resulting in a pregnancy rate of $12.74 \%$ ( $n=13$ cycles).

\section{DISCUSSION}

Various parameters were analyzed in this study, including female patient age, ovulation induction method, cause of infertility, number of mature follicles, and number of sperm with progressive motility, but only age was significantly related to successful IUI.

Although ovulation was induced based on the procedure indicated for each patient (IUI or IVF), no difference was found in the outcome of pregnancy between induction methods. Fifteen clinical pregnancies occurred in the 179 cycles $(83.33 \%)$ indicated for IUI, whereas three pregnancies occurred in the 58 cycles indicated for IVF (16.67\%). This finding agrees with two studies that showed no significant differences in chemical and clinical pregnancy rates between intracytoplasmic sperm injection and patients converted to IUI (Shahine et al., 2009; Shohieb et al., 2012). Another study reported higher clinical pregnancy rates among individuals converted from IVF to IUI than in the group offered IVF. This suggests that conversion from 
Table 1. Clinical and laboratory characteristics of 237 Intrauterine Insemination cycles

\begin{tabular}{|c|c|c|c|c|c|c|}
\hline Variable & $\operatorname{Mean}( \pm$ SD*) & Median & $\mathbf{Q 1}^{+}$ & $\mathbf{Q 3}^{*}$ & Minimum & Maximum \\
\hline Age (years) & $36.32(5.1)$ & 36 & 33 & 40 & 23 & 48 \\
\hline Concentration sptz pre processing $\left(\times 10^{6}\right)$ & $81.09(59.73)$ & 65.5 & 37.5 & 117 & 1.8 & 313.5 \\
\hline Progressive motility & $28.4(14.01)$ & 28 & 19 & 38 & 0 & 66 \\
\hline Concentration sptz post processing $\left(\times 10^{6}\right)$ & $74.86(58.27)$ & 62 & 32.5 & 103 & 0.2 & 329.5 \\
\hline Progressive motility post processing $\left(\times 10^{6}\right)$ & $58.84(14.88)$ & 60 & 51 & 70 & 8 & 91 \\
\hline Concentration of recovered sptz & $23.83(21.93)$ & 18.2 & 7.5 & 31.98 & 0.08 & 131.8 \\
\hline Number of mature follicles $(\geq 17 \mathrm{~mm})$ & $1.14(0.38)$ & 1 & 1 & 1 & 1 & 3 \\
\hline
\end{tabular}

Sptz=sperm,

* Standard deviation,

+ First quartile,

* Third quartile

Table 2. Clinical and laboratory characteristics of 237 Intrauterine Insemination cycles versus pregnancy outcome

\begin{tabular}{|l|c|c|c|}
\hline \multirow{2}{*}{ Age } & \multicolumn{2}{|c|}{ Pregnancy } & \multirow{2}{*}{ P-value } \\
\cline { 2 - 3 } & No & Yes & \\
\hline $\begin{array}{l}\text { Concentration sptz } \\
\text { preprocessing }\end{array}$ & $\begin{array}{c}36.63 \\
(5.03)\end{array}$ & $\begin{array}{c}72.56 \\
(4.64)\end{array}$ & 0.001 \\
\hline $\begin{array}{l}\text { Progressive motility } \\
\text { pre processing }\end{array}$ & $\begin{array}{c}\text { 28.26 } \\
(101.64\end{array}$ & $\begin{array}{c}\text { 30 } \\
(85.25)\end{array}$ & 0.129 \\
\hline $\begin{array}{l}\text { Concentration sptz } \\
\text { post processing }\end{array}$ & $\begin{array}{c}74.82 \\
(58.55)\end{array}$ & $\begin{array}{c}75.38 \\
(56.4)\end{array}$ & 0.614 \\
\hline $\begin{array}{l}\text { Progressive motility } \\
\text { post processing }\end{array}$ & $\begin{array}{c}58.58 \\
(15.06)\end{array}$ & $\begin{array}{c}62.19 \\
(12.12)\end{array}$ & 0.351 \\
\hline $\begin{array}{l}\text { Concentration of } \\
\text { recovered sptz }\end{array}$ & $\begin{array}{c}23.75 \\
(22.02)\end{array}$ & $\begin{array}{c}24.88 \\
(21.39)\end{array}$ & 0.841 \\
\hline
\end{tabular}

Sptz=sperm

IVF to IUI is a valid alternative for poor respondents (Freour et al., 2010). In contrast with these findings, a 2010 study showed that, in certain cases, IVF yielded higher pregnancy rates when compared to conversion to IUI (Norian et al., 2010). As illustrated by these studies, there is still no consensus in the literature regarding conversion to IUI for cycles with induced ovulation and poor response during follicular recruitment in ovulation induction for IVF.

Patient age was the only statistically significant variable observed in our study. In line with our findings, previous studies have shown that there is a decrease in clinical pregnancy rates as the age of patients undergoing IUI increases (Zadehmodarres et al., 2009; Ghaffari et al., 2015; Honda et al., 2015). Merviel et al. (2010) and Azantee et al. (2011) reported that patients aged $<30$ years have a better chance of achieving pregnancy. In our study, the patients considered ideal for IUI were aged $\leq 35$ years and yielded a pregnancy rate of $12.74 \%$. Ashrafi et al. (2013), however, found no association between declining pregnancy rates and increasing age for women aged $<40$ years, indicating that IUI is also a good alternative for patients aged 40 years and younger. Moreover, some studies have emphasized that female patient age is the most important prognostic factor in the success of IUI after a period of infertility (Yousefi \& Azargon, 2011). However, some studies found no association between patient age and outcomes of clinical pregnancy for IUI (Ibérico et al., 2004; Erdem et al., 2008; Akl et al., 2011; Wu et al., 2013).

Causes of infertility were not related to successful pregnancy in our study group. Some studies have found higher rates of clinical pregnancy with IUI in patients with unexplained infertility (Merviel et al., 2010; Azantee et al., 2011; Ombelet, 2013), moderate masculinity, and ovulatory disorders (Merviel et al., 2010; Azantee et al., 2011; Dinelli et al., 2014; Ghaffari et al., 2015). Causes of infertility such as endometriosis and tubal factor, however, produced negative effects and lower pregnancy rates after IUI (Merviel et al., 2010; Wu et al., 2013; Ghaffari et al., 2015).

The number of recruited mature follicles was not correlated with clinical pregnancy rates in this study, although the proportion of cycles with more than one recruited follicle was very low, possibly due to the low doses of ovulation induction drugs used in our protocols. Interestingly, among the cycles that achieved clinical pregnancy, approximately $89 \%$ had only one mature follicle. In agreement with our study, Akl et al. (2011) and Wu et al. (2013) did not find significant differences between the results of IUI and the number of mature follicles. However, these studies revealed that greater numbers of mature follicles were correlated with higher clinical pregnancy rates. A study conducted in 2013 reported a pregnancy rate of $22.5 \%$ in cycles with three preovulatory follicles and of $6.5 \%$ in cycles with a single follicle (Ashrafi et al., 2013). In a cross-sectional analysis, Ibérico et al. (2004) reported that the application of IUI in cycles with three mature follicles almost tripled pregnancy rates when compared to cycles with only one follicle. In a literature review, Merviel et al. (2010) reported that the strongest predictive factor for pregnancy after IUI was ovulation stimulation enabling the recruitment of at least two follicles $>16 \mathrm{~mm}$.

Our study also looked into the pre- and post-processing number of sperm with progressive motility, and found no association between these parameters and clinical pregnancy rates. Accordingly, studies by Akl et al. (2011), Ghaffari et al. (2015), Luco et al. (2014), and Ombelet et al. (2014) indicated that sperm parameters did not significantly affect IUI success. In contrast, other authors including Azantee et al. (2011) reported that sperm parameters were correlated with IUI success, adding that one of the more significant prognostic factors for the success of the procedure was semen quality, as patients with low sperm counts (oligospermia) and low counts of sperm with progressive motility (asthenozoospermia) had more adverse IUI results (Barros Delgadillo et al., 2006).

Another variable that might influence the outcome is total motile sperm count (TMSC), which is the product of 
Table 3. Clinical and laboratory characteristics of 237 intrauterine insemination cycles versus type of ovulation induction

\begin{tabular}{|c|c|c|c|}
\hline & $\begin{array}{c}\text { Ovulation monitoring for } \\
\text { IUI }(N=179)\end{array}$ & $\begin{array}{l}\text { Ovulation monitoring for } \\
\text { IVF }(\mathrm{N}=58)\end{array}$ & P-value \\
\hline $\begin{array}{l}\text { Number of mature follicles } \\
(\geq 17 \mathrm{~mm})\end{array}$ & & & \multirow{4}{*}{0.5789} \\
\hline 1 & $155(86.59)$ & $52(89.66)$ & \\
\hline 2 & $21(11.73)$ & $6(10.34)$ & \\
\hline 3 & $3(1.68)$ & $0(0.00)$ & \\
\hline Age & $35.41(5.16)$ & $39.12(3.73)$ & 0.0001 \\
\hline Sptz progressive motility & $59.11(14.71)$ & $58.03(15.45)$ & 0.8437 \\
\hline Concentration of recovered sptz & $24.27(21.89)$ & $22.49(22.21)$ & 0.7493 \\
\hline
\end{tabular}

Sptz=sperm, IUI=intrauterine insemination, IVF=in vitro fertilization

Table 4. Causes of infertility of 237 cycles of intrauterine insemination versus pregnancy outcome

\begin{tabular}{|l|c|c|}
\hline Causes of infertility & $\begin{array}{c}\text { IUI cycles } \\
(\mathbf{N}=\mathbf{2 3 7})\end{array}$ & $\begin{array}{c}\text { Clinical } \\
\text { pregnancy } \\
(\mathbf{N = 1 8 )}\end{array}$ \\
\hline Unexplained infertility & $60(25.32 \%)$ & $5(27.78 \%)$ \\
\hline Low ovarian reserve & $45(18.99 \%)$ & $2(11.11 \%)$ \\
\hline Ovulation factor & $41(17.3 \%)$ & $6(33.33 \%)$ \\
\hline Male factor & $39(16.46 \%)$ & $2(11.11 \%)$ \\
\hline Endometriosis & $31(13.08 \%)$ & $1(5.56 \%)$ \\
\hline Others & $16(6.75 \%)$ & $2(11.11 \%)$ \\
\hline Tubal factor & $5(2.11 \%)$ & 0 \\
\hline
\end{tabular}

IUI=intrauterine insemination

the sperm volume collected based on sperm concentration and the percentage of sperm with progressive motility in the ejaculate (Nikbakht \& Saharkhiz, 2011). However, due to a partial lack of data, this variable was not calculated in our study. Some authors reported that higher total motile sperm counts lead to greater likelihood of pregnancy after IUI (Ibérico et al., 2004; Merviel et al., 2010; Yousefi \& Azargon, 2011). Nikbakht \& Saharkhiz (2011) evaluated the prognostic value of TMSC and the number of motile sperm inseminated (NMSI) in IUI, and showed that pregnancy rates were higher when the TMSC ranged between $5 \times 10^{6}$ and $10 \times 10^{6}(15 \%)$, and lower in subgroups that had counts $<1 \times 10^{6}$, from $1 \times 10^{6}$ to $<5 \times 10^{6}$, and $\geq 10 \times 10^{6}$ (5.6\%; $5.1 \% ; 10.8 \%$ respectively). NMSI $\geq 10 \times 10^{6}$ resulted in higher pregnancy rates $(11.2 \%)$ versus subgroups with counts $<5 \times 10^{6}$ and from $5 \times 10^{6}$ to $<10 \times 10^{6}(4.1 \%$ and $5.2 \%$, respectively). Supporting Nikbakht \& Saharkhiz (2011), Lemmens et al. (2016) reported that IUI is particularly relevant for couples with NMSI ranging from 5 to $10 \times 10^{6}$.

It has been shown that pregnancy rates may vary significantly depending on the number of motile sperm inseminated (Badawy et al., 2009; Merviel et al., 2010; Cao et al., 2014). Dinelli et al. (2014) reported that the main problem related to male infertility was moderated asthenozoospermia, and that pregnancy rates were significantly higher when the number of motile sperm with progressive motility used in insemination was at least $1 \times 10^{6}$.

Finally, although the clinical pregnancy rate seen in our population was $7.59 \%$, the subgroup of patients thought to have ideal conditions for intrauterine insemination (age $\leq 35$ years, unexplained infertility, ovarian factor infertility or minimal endometriosis, and partners with sperm count $\geq 2.5 \times 10^{6}$ retrieved on the day of insemination) had a pregnancy rate of $12.74 \%$. Geisler et al. (2017) recently aimed to find the factors that might support more individualized applications of IUI, and reported that IUI associated with controlled ovarian hyperstimulation, especially in younger patients, produced good live birth rates. More than $90 \%$ of the live births with IUI were achieved during the first two cycles. Our findings for this age group were similar, in that younger patients had better pregnancy results with IUI. These findings suggest that probabilities of success may be used to individualize treatment decisions, while IUI before IVF for carefully chosen patients still is a treatment option.

A possible limitation of our study was the size of the sample, which may not have been large enough to detect differences in some of the analyzed parameters. Further studies with larger sample sizes may be necessary to confirm the results of this study.

\section{CONCLUSION}

The clinical pregnancy rate found in this study was $7.59 \%$. When ideal conditions were present for the indication of IUI, the pregnancy rate was $12.74 \%$. Female patient age was the only variable significantly associated with IUI success. Ovulation induction method, cause of infertility, number of mature follicles, and number of sperm with progressive motility were not associated with pregnancy outcome. Due to affordability and when accompanied by appropriate patient selection, IUI remains an effective method among the available options for infertile couples.

\section{CONFLICT OF INTERESTS}

No conflict of interest has been declared.

\section{ACKNOWLEDGEMENTS}

The authors wish to thank Marilda Hatsumi Yamada Dantas for her technical support and Viviane Santana Paiva for revising the manuscript.

\section{Corresponding author}

Rosana Maria Reis

Ribeirão Preto Medical School

São Paulo University

Ribeirão Preto, SP, Brazil.

E-mail: romareis@fmrp.usp.br 


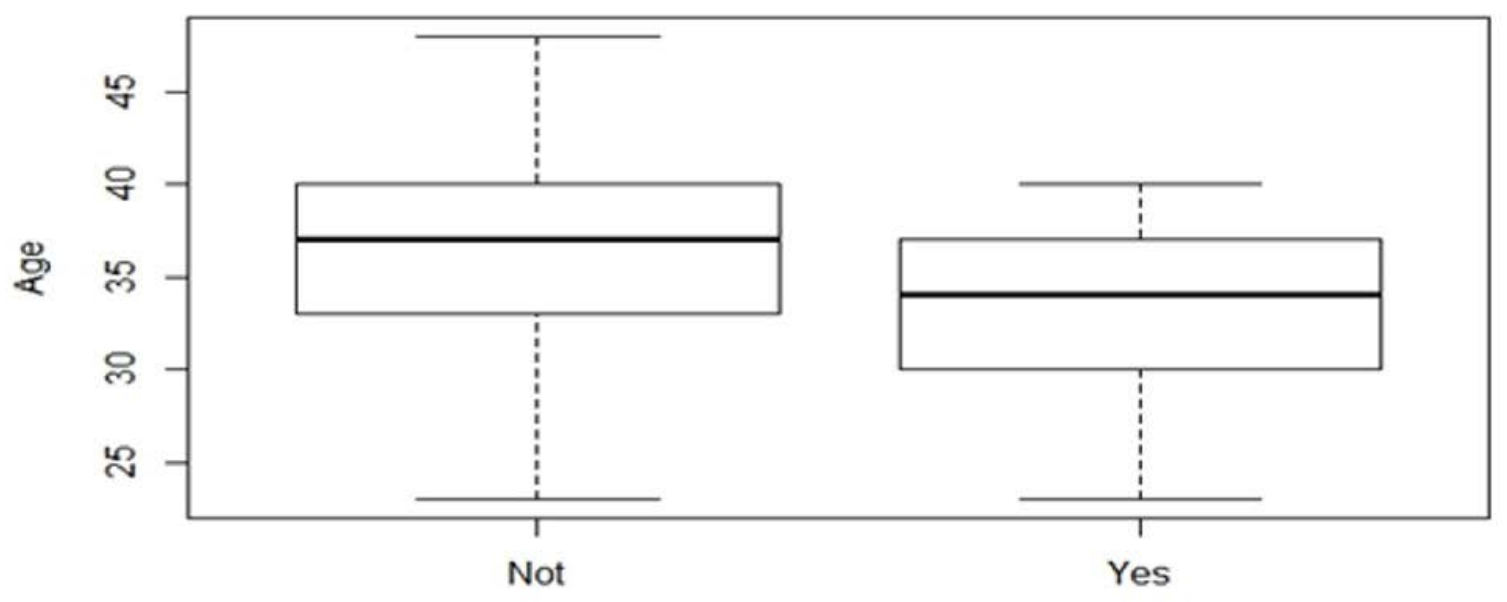

Pregnancy

Figure 1. Mean age of patients submitted to intrauterine insemination versus pregnancy outcome

\section{REFERENCES}

AkI LD, Oliveira JB, Petersen CG, Mauri AL, Silva LF, Massaro FC, Baruffi RL, Cavagna M, Franco JG Jr. Efficacy of the motile sperm organelle morphology examination (MSOME) in predicting pregnancy after intrauterine insemination. Reprod Biol Endocrinol. 2011;9:120. PMID: 21861903 DOI: $10.1186 / 1477-7827-9-120$

Ashrafi M, Rashidi M, Ghasemi A, Arabipoor A, Daghighi S, Pourasghari $P$, Zolfaghari $Z$. The role of infertility etiology in success rate of intrauterine insemination cycles: an evaluation of predictive factors for pregnancy rate. Int J Fertil Steril. 2013;7:100-7. PMID: 24520471

Azantee YW, Murad ZA, Roszaman R, Hayati MY, Norsina MA. Associated factors affecting the successful pregnancy rate of intrauterine insemination at International Islamic University Malaysia (IIUM) Fertility Centre. Med J Malaysia. 2011;66:195-8. PMID: 22111439

Badawy A, Elnashar A, Eltotongy M. Effect of sperm morphology and number on success of intrauterine insemination. Fertil Steril. 2009;91:777-81. PMID: 18304534 DOI: $10.1016 /$ j.fertnstert.2007.12.010

Barros Delgadillo JC, Rojas Ruiz JC, Molina Munguía AC, Villalobos Acosta S, Sánchez Solís V, Barroso Villa G, Gaviño Gaviño F. Prognostic factors of pregnancy in intrauterine insemination. Ginecol Obstet Mex. 2006;74:611-25. PMID: 17539317

Cao S, Zhao C, Zhang J, Wu X, Zhou L, Guo X, Shen R, Ling $X$. A minimum number of motile spermatozoa are required for successful fertilisation through artificial intrauterine insemination with husband's spermatozoa. Andrologia. 2014;46:529-34. PMID: 23701485 DOI: 10.1111/and.12109

Dinelli L, Courbière $B$, Achard V, Jouve $E$, Deveze C, Gnisci A, Grillo JM, Paulmyer-Lacroix O. Prognosis factors of pregnancy after intrauterine insemination with the husband's sperm: conclusions of an analysis of 2,019 cycles. Fertil Steril. PMID: 24534285 DOI: 10.1016/j.fertnstert.2014.01.009
Erdem A, Erdem M, Atmaca S, Korucuoglu U, Karabacak O. Factors affecting live birth rate in intrauterine insemination cycles with recombinant gonadotrophin stimulation. Reprod Biomed Online. 2008;17:199-206. PMID: 18681993 DOI: 10.1016/S1472-6483(10)60195-2

European IVF-Monitoring Consortium (EIM); European Society of Human Reproduction and Embryology (ESHRE), Kupka MS, D'Hooghe T, Ferraretti AP, de Mouzon J, Erb K, Castilla JA, CalhazJorge C, De Geyter Ch, Goossens V. Assisted reproductive technology in Europe, 2011: results generated from European registers by ESHRE. Hum Reprod. 2016;31:233-48. PMID: 26740578 DOI: $10.1093 /$ humrep/dev319

Fauque $P$, Lehert $P$, Lamotte $M$, Bettahar-Lebugle $K$, Bailly $A$, Diligent $C$, Clédat $M$, Pierrot $P$, Guénédal $M L$, Sagot P. Clinical success of intrauterine insemination cycles is affected by the sperm preparation time. Fertil Steril. 2014;101:1618-23.e1-3. PMID: 24745729 DOI: 10.1016/j.fertnstert.2014.03.015

Ferraretti AP, Goossens V, de Mouzon J, Bhattacharya S, Castilla JA, Korsak V, Kupka M, Nygren KG, Nyboe Andersen A; European IVF-monitoring (EIM); Consortium for European Society of Human Reproduction and Embryology (ESHRE). Assisted reproductive technology in Europe, 2008: results generated from European registers by ESHRE. Hum Reprod. 2012;27:2571-84. PMID: 22786779 DOI: $10.1093 /$ humrep/des255

Freour T, Dubourdieu S, Mirallie S, Langlois $M L$, Jean $M$, Barrière $P$. IVF conversion to IUI in poor responders: an observational study. Arch Gynecol Obstet. 2010;282:4459. PMID: 20499076 DOI: 10.1007/s00404-010-1515-0

Geisler ME, Ledwidge M, Bermingham M, McAuliffe $M$, McMenamin MB, Waterstone JJ. Intrauterine inseminationNo more Mr. N.I.C.E. guy? Eur J Obstet Gynecol Reprod Biol. 2017;210:342-7. PMID: 28122315 DOI: 10.1016/j.ejogrb.2017.01.016

Ghaffari F, Sadatmahalleh SJ, Akhoond MR, Eftekhari Yazdi $P$, Zolfaghari Z. Evaluating The Effective Factors in Pregnancy after Intrauterine Insemination: A Retrospective Study. Int J Fertil Steril. 2015;9:300-8. PMID: 26644852 DOI: $10.22074 /$ ijfs.2015.4544 
Honda T, Tsutsumi M, Komoda F, Tatsumi K. Acceptable pregnancy rate of unstimulated intrauterine insemination: a retrospective analysis of 17,830 cycles. Reprod Med Biol. 2015;14:27-32. PMID: 25598699 DOI: $10.1007 / \mathrm{s} 12522-014-0192-2$

Ibérico G, Vioque J, Ariza N, Lozano JM, Roca M, Llácer J, Bernabeu R. Analysis of factors influencing pregnancy rates in homologous intrauterine insemination. Fertil Steril. 2004;81:1308-13. PMID: 15136095 DOI: 10.1016/j.fertnstert.2003.09.062

Lemmens L, Kos S, Beijer C, Brinkman JW, van der Horst FA, van den Hoven $L$, Kieslinger DC, van Trooyen-van Vrouwerff NJ, Wolthuis A, Hendriks JC, Wetzels AM; Semen Section of the Dutch Foundation for Quality Assessment in Medical Laboratories. Predictive value of sperm morphology and progressively motile sperm count for pregnancy outcomes in intrauterine insemination. Fertil Steril. 2016;105:14628. PMID: 26930619 DOI: 10.1016/j.fertnstert.2016.02.012

Luco SM, Agbo C, Behr B, Dahan MH. The evaluation of pre and post processing semen analysis parameters at the time of intrauterine insemination in couples diagnosed with male factor infertility and pregnancy rates based on stimulation agent. A retrospective cohort study. Eur J Obstet Gynecol Reprod Biol. 2014;179:159-62. PMID: 24965998 DOI: $10.1016 /$ j.ejogrb.2014.05.003

Merviel P, Heraud MH, Grenier N, Lourdel E, Sanguinet $P$, Copin $\mathrm{H}$. Predictive factors for pregnancy after intrauterine insemination (IUI): an analysis of 1038 cycles and a review of the literature. Fertil Steril. 2010;93:79-88. PMID: 18996517 DOI: $10.1016 /$ j.fertnstert.2008.09.058

Nikbakht $R$, Saharkhiz N. The influence of sperm morphology, total motile sperm count of semen and the number of motile sperm inseminated in sperm samples on the success of intrauterine insemination. Int J Fertil Steril. 2011;5:168-73.
Norian JM, Levens ED, Richter KS, Widra EA, Levy MJ. Conversion from assisted reproductive technology to intrauterine insemination in low responders: is it advantageous? Fertil Steril. 2010;94:2073-7. PMID: 20171626 DOI: 10.1016/j.fertnstert.2009.12.056

Ombelet W. Evidence-based recommendations for IUI in daily practice. Middle East Fertil Soc J. 2013;18:74-7. DOI: 10.1016/j.mefs.2013.01.001

Ombelet W, Dhont N, Thijssen A, Bosmans E, KrugerT. Semen quality and prediction of IUI success in male subfertility: a systematic review. Reprod Biomed Online. 2014;28:300-9. PMID: 24456701 DOI: $10.1016 /$ j.rbmo.2013.10.023

Shahine LK, Lathi RB, Baker VL. Oocyte retrieval versus conversion to intrauterine insemination in patients with poor response to gonadotropin therapy. Fertil Steril. 2009;92:1315-7. PMID: 19393998 DOI: 10.1016/j.fertnstert.2009.03.059

Shohieb A, Mostafa M, El-Khayat W. Conversion of ICSI cycles to IUI in poor responders to controlled ovarian hyperstimulation. Middle East Fertil Soc J. 2012;17:42-6. DOI: $10.1016 /$ j.mefs.2011.07.005

Wu HM, Tzeng $\mathrm{CR}$, Chen $\mathrm{CH}$, Chen $\mathrm{PH}$. Pelvic endometriosis with peritoneal fluid reduces pregnancy rates in women undergoing intrauterine insemination. Taiwan J Obstet Gynecol. 2013;52:512-5. PMID: 24411035 DOI: 10.1016/j.tjog.2013.10.010

Yousefi B, Azargon A. Predictive factors of intrauterine insemination success of women with infertility over 10 years. J Pak Med Assoc. 2011;61:165-8. PMID: 21375168

Zadehmodarres S, Oladi B, Saeedi S, Jahed F, Ashraf $\mathrm{H}$. Intrauterine insemination with husband semen: an evaluation of pregnancy rate and factors affecting outcome. J Assist Reprod Genet. 2009;26:7-11. DOI: $10.1007 / \mathrm{s} 10815-008-9273-7$ 